\title{
DESCARTE DO LIXO DE UM HOSPITAL PÚBLICO NO MUNICÍPIO DE COARI, ESTADO DO AMAZONAS, BRASIL
}

\section{DISCARD OF THE GARBAGE OF A PUBLIC HOSPITAL IN THE MUNICIPAL DISTRICT OF COARI, STATE OF THE AMAZON, BRAZIL}

Célio dos Santos Almeida celioalmeida08@gmail.com
colmal

Helder Manuel da Costa Santos

Doutorado em Geologia pela Universidade Federal do Rio de Janeiro hmcsantos@yahoo.com.br

\author{
Graduando do Curso de Licenciatura em Ciências: Biologia e Química da Universidade Federal do Amazonas \\ gnangoes@gmail.com \\ Vanusa Bezerra Pachêco \\ Doutorado em Física Atômica e Molecular pela Universidade Federal de São Carlos \\ vanusafis@ufam.edu.br
}

\begin{abstract}
RESUMO
Este trabalho trata-se de uma pesquisa realizada sobre o gerenciamento dos resíduos de um hospital público no município de Coari-AM com o objetivo de analisar o modo como os resíduos são descartados e verificar se os procedimentos estão em conformidade com as exigências legais das resoluções brasileiras que dispõem sobre o gerenciamento do lixo hospitalar. A pesquisa foi realizada na área externa do hospital onde foi observado os tipos de resíduos descartados na lixeira externa, a forma de armazenamento, segregação, identificação, coleta e transporte até a disposição final. A lixeira armazenava resíduos do Grupo A (infectantes), Grupo D (comum) e Grupo E (perfurocortantes) em sacos plásticos ou em caixas de papelão e que, posteriormente, eram despejados no lixão. Foi constatado que o hospital descumpre as orientações determinadas pela Resolução da Diretoria Colegiada $n^{\circ}$ 222/2018 da Agência Nacional de Vigilância Sanitária e Resolução n 358/2005 do Conselho Nacional do Meio Ambiente sobre o descarte de seus resíduos.
\end{abstract}

Palavras-chave: Lixo hospitalar. Descarte. Coari.

\begin{abstract}
This work is treated of a research accomplished on the administration of the residues of a public hospital in the municipal district of Coari-AM with the objective of analyzing the way as the residues they are discarded and to verify the procedures is in conformity with the legal demands of the Brazilian resolutions that dispose on the administration of the garbage hospitalar. The research was accomplished in the area it expresses of the hospital where was observed the types of discarded residues in the garbage can it expresses, the storage form, segregation, identification, collects and transport until the final disposition. The garbage can stored residues of the Group THE (infectantes), I Group D (common) and I Group AND (perfurocortantes) in plastic sacks or in cardboard boxes and that, later, they were spilled in the lixão. It was verified that the hospital descumpre the certain orientations for the Resolution of the Management Colegiada $n^{\circ} 222 / 2018$ of the National Agency of Sanitary Surveillance and Resolution $n^{\circ} 358 / 2005$ of the National Council of the environment on the discard of your residues.
\end{abstract}

Keywords: hospital trash. Discard. Coari.

Recebido em: 10/08/2020

Aceito para publicação em: 19/10/2020. 
Descarte do lixo de um hospital público no município de Coari, estado do Amazonas, Brasil
Célio dos Santos Almeida Helder Manuel da Costa Santos Dartaguinan da Silva Góes Vanusa Bezerra Pachêco

\section{INTRODUÇÃO}

O consumo e o crescimento da população têm gerado um agravamento sobre a disposição do lixo nos centros urbanos, cujos despejos na maioria dos municípios ainda ocorrem nos lixões, aterros controlados ou aterros sanitários (MEDEIROS et al., 2008). Além dos grandes volumes gerados, o descarte inadequado do lixo tem colocado em risco o meio ambiente, como contaminação dos lençóis freáticos, incêndios, explosões provocadas pelos gases e, além disso, tem se transformado em um problema de saúde pública de acordo com Neto et al. (2007).

A preocupação aumenta quando se trata dos resíduos dos serviços de saúde que se torna um grande desafio ao gerenciamento por empresas especializadas e pelo poder público, uma vez que apresentam a capacidade de infectar e contaminar o meio ambiente e a qualidade de vida do ser humano (SPINA, 2005; SANTANA, 2016).

Devido isso, é preciso que os hospitais tenham um plano de gerenciamento dos resíduos de serviços de saúde estabelecidos para o seu descarte de forma segura, pois a inadimplência referente a esse tipo de despejo trará vários prejuízos ambientais e sociais (POZZETTI e MONTEVERDE, 2017). Esse plano deve contemplar os procedimentos corretos para o manejo dos resíduos, como a segregação, acondicionamento, armazenamento, identificação, tratamento, coleta e disposição final, de modo a garantir a segurança quanto aos riscos de contaminação da população e do meio ambiente (SOUZA, 2011).

Os resíduos dos serviços de saúde são aqueles gerados e descartados pelos estabelecimentos relacionados ao atendimento de saúde humana ou animal, tais como farmácias, funerárias, postos de saúde, hospitais, necrotérios, clínicas médicas e outras instituições das áreas de saúde (GESSNER et al., 2013; BARROS et al., 2020). Segundo Haddad (2006) a taxa de descarte por hospitais, postos de saúde, clínicas médicas e outras similares corresponde cerca de $1 \%$ da produção total gerados no país. Mesmo assim, as instituições são responsáveis e devem elaborar um plano de gerenciamento de resíduos de serviços de saúde, respeitando as características infectantes, químicas, perfurocortantes e comum (BARROS et al., 2010).

O plano de gerenciamento do lixo hospitalar é uma forma de assegurar a integridade da saúde pública e ambiental quando gerenciado em conformidade com o que estabelece as legislações (BORGES et al., 2016). Além de comportar os pacientes, os hospitais geram e descartam resíduos que são considerados perigosos à saúde pública e ao meio ambiente. Por isso, existem leis rigorosas que punem os estabelecimentos de saúde que não estão atendendo as normas vigentes para seu gerenciamento.

No Brasil, os resíduos dos serviços de saúde recebem da Agência Nacional de Vigilância Sanitária (ANVISA) e do Conselho Nacional de Meio Ambiente (CONAMA) normas vigentes quanto sua classificação e seu gerenciamento para tratamento, segregação, acondicionamento, identificação, armazenamento, coleta, transporte e destino final (COSTA e FONSECA, 2009).

Apesar dos riscos, ainda existem unidades de saúde que não cumprem com a legislação, pois a cada dia é notado o gerenciamento inadequado que é dado aos resíduos sólidos hospitalares do Grupo A (infectantes), como restos de tecido humano, placenta, resíduos pós-aborto, bolsa de hemoderivados e prótese que são descartados em lixeira comum sem a menor preocupação dos impactos que podem causar no ambiente e a saúde pública (CAFURE e GRACIOLLI, 2015).

As legislações sobre o gerenciamento dos resíduos hospitalares, como Normas e Resoluções, visam a sustentabilidade ambiental e a preservação da saúde pública (MADERS e CUNHA, 2015). O desconhecimento e a falta de informações relacionados ao gerenciamento do lixo hospitalar e, especialmente, sobre o seu descarte final, que pode ser o lixão, gera questionamentos e preocupações pelos aspectos éticos e técnicos com repercussões ambientais e de saúde pública por serem mais perigosos que os resíduos domiciliares.

De acordo com a Resolução da Diretoria Colegiada (RDC) $n^{\circ} 222$ de Março de 2018 da Agência Nacional de Vigilância Sanitária (ANVISA) e da Resolução n ${ }^{\circ} 358$ de 25 de Abril de 2005 do Conselho Nacional do Meio Ambiente (CONAMA), os resíduos dos serviços de saúde são classificados considerando 5 grupos: $O$ grupo A (resíduos infectantes) que por sua vez, podem conter agentes infectuosos capazes de causar infecções a saúde, como bolsas de sangue contaminada, restos de órgãos e dentre outros (COTRIM, SLOB e DEFFUNE, 2012). Grupo B (resíduos químicos) contém substância capazes de prejudicar a saúde pública e ao meio ambiente dependendo das características

DOI: http://dx.doi.org/10.14393/Hygeia16056612 $\quad$ Hygeia $\quad$ v.16 $\quad$ p. 362 - 372, 2020 página 363


Descarte do lixo de um hospital público no município de Coari, estado do Amazonas, Brasil
Célio dos Santos Almeida Helder Manuel da Costa Santos Dartaguinan da Silva Góes Vanusa Bezerra Pachêco

de corrosividade, inflamabilidade, reatividade e toxicidade, como remédios vencidos, entre outros (SALLES, 2008). Grupo C (resíduos radioativos) são os rejeitos que apresentam alto grau de radioatividade aos limites de eliminação especificados pelo Centro de Nacional de Energia Nuclear, como serviços de medicina nuclear e radioterapia (MACHADO e MORAES, 2004). Grupo D (resíduo comum) são resíduos que não apresentam risco biológico, químico ou radiológico à saúde e ao meio ambiente, sendo equiparados aos resíduos domiciliares, como papel, gesso, luvas, papelão, dentre outros (ALVES, 2010). Grupo E (resíduos perfurocortantes) são os resíduos que podem cortar e furar, como agulhas, bisturis e lâminas e outros similares do serviço de saúde (ERDTMANN, 2004).

As instituições de saúde, inevitavelmente, produzem e despejam vários tipos de resíduos e, por isso, é importante refletir nos diferentes grupos gerados, pois ações inadequadas no manejo e, especialmente, a destinação final podem provocar problemas ambientais como a contaminação do solo, ar e água superficial, subterrânea, riscos à saúde humana ou até a morte (MENDES, 2005).

O treinamento dos funcionários e o gerenciamento adequado dos resíduos hospitalares gerados é importante porque leva a adequada coleta, tratamento e disposição final, reduzindo os acidentes e os impactos ambientais (GARCIA e RAMOS, 2004).

O lixo hospitalar representa um sério problema para os gestores e funcionários do setor da saúde, pacientes, familiares, dos trabalhadores que coletam o lixo e dos que trabalham ou frequentam os lixões ou os locais onde são despejados. As preocupações estão voltadas aos prejuízos que podem causar na saúde humana e no meio ambiente (CAMARGO et al., 2009).

Nesse sentido, as pesquisas devem ser desenvolvidas no sentido de alertar sobre os riscos e ao mesmo tempo buscar soluções para evitar acidentes com o lixo hospitalar. No cenário atual, os resíduos gerados pelo hospital da região no município de Coari-AM ainda são pouco estudados e, por isso, motivou a realização da presente pesquisa com o objetivo de analisar o gerenciamento dos mesmos e verificar se os procedimentos sobre o despejo estão em conformidade com as exigências legais das resoluções brasileiras que dispõem sobre o lixo hospitalar. Por outro lado, com os resultados pretendese subsidiar de informações as autoridades responsáveis locais e a população para o gerenciamento correto destes resíduos, levando em consideração as legislações vigentes.

\section{METODOLOGIA}

O estudo é caracterizado como pesquisa descritiva que segundo Prodanov e Freitas (2013) tem como objetivo a descrição das características de determinada população ou fenômeno estudado, registrar e descrever os fatos observados sem interferência do pesquisador. Além disso, é caracterizada como estudo de campo com bases nos procedimentos técnicos, que de acordo com Gil (2002) constitui um modelo clássico de investigação por procurar o aprofundamento das questões propostas a ser desenvolvido no local em que estão correndo os fenômenos. E também, é qualitativa quanto a natureza dos dados, pois preocupa-se com a interpretação e compreensão dos mesmos, considerando o significado que os outros dão a sua prática, o que impõe ao pesquisador uma análise interpretativa (GONSALVES, 2001).

Para a coleta de dados foi utilizada a observação assistemática segundo os meios utilizados conforme Marconi e Lakatos (2003). É uma técnica não planejada, sem controle previamente elaborado e que permite registrar fatos da realidade e recolher os dados sem que o pesquisador precise usar meios técnicos especiais ou fazer perguntas diretas. Também, segundo Zambello et al. (2018) a participação da observação é caracterizada do tipo não participativa que presencia o fato e tem a contento com a comunidade ou a realidade estudada, porém sem interferir nas atividades. Ainda, empregou-se a modalidade em grupo quanto ao número de observações, que de acordo com Marconi e Lakatos (2003) pode-se analisar a ocorrências em vários ângulos na mesma área, possibilitando o confronto dos dados para verificar as predisposições.

A pesquisa foi realizada no período de novembro de 2016 a agosto de 2020 e concentrou-se na lixeira externa de um hospital público da região no município de Coari-AM, devido à facilidade de acesso da sua localização. A unidade hospitalar é muito importante na Região do Médio Solimões, pois atende a população da cidade, das comunidades ribeirinhas do município de Coari e dos municípios próximos. Embora seja do poder estadual, tem sob a responsabilidade do Governo Municipal a administração e o gerenciamento dos resíduos hospitalares. 
Descarte do lixo de um hospital público no município de Coari, estado do Amazonas, Brasil
Célio dos Santos Almeida Helder Manuel da Costa Santos Dartaguinan da Silva Góes

Vanusa Bezerra Pachêco

Coari é um município do interior do Estado do Amazonas, Região Norte do Brasil, possui uma área territorial de $57.922 \mathrm{Km}^{2}$ e está situado no Médio Solimões a $363 \mathrm{~km}$ da capital Manaus com uma população estimada em 85.097 habitantes de acordo com o IBGE (2019).

$\mathrm{Na}$ lixeira externa do hospital, observou-se e registrou-se o tipo de lixo descartado, a forma de acondicionamento, armazenamento, identificação, segregação, coleta e transporte externo até a disposição final. Além disso, visitou-se o lixão da cidade, destino final dos resíduos, e observou-se a maneira como são manuseados, especialmente, os resíduos hospitalares.

A análise dos dados foi feita seguindo a Resolução da Diretoria Colegiada (RDC) $n^{\circ} 222$ de 28 de Março de 2018 da Agência Nacional de Vigilância Sanitária (ANVISA) que regulamenta as boas práticas de gerenciamento dos resíduos de serviços de saúde e Resolução $n^{\circ} 358$ de 25 de Abril de 2005 do Conselho Nacional de Meio Ambiente (CONAMA) que dispõe sobre o tratamento e a disposição final dos resíduos dos serviços de saúde, visando analisar se as etapas concernentes ao descarte do lixo do hospital cumprem com as exigências dispostas nas resoluções.

\section{RESULTADOS E DISCUSSÃO}

O lixo hospitalar, por si só, gera sérias preocupações pelas suas características de apresentar riscos de contaminação e infecção. As preocupações foram maiores quando constatados desvios e irregularidades no gerenciamento dos resíduos do hospital em Coari. Durante a pesquisa, observou-se que a lixeira externa do hospital continha resíduos do Grupo A (infectantes), Grupo D (comum) e Grupo $\mathrm{E}$ (perfurocortantes) que ficavam armazenados no local até os funcionários responsáveis pela coleta externa recolherem para o despejo no lixão (tabela 1).

Tabela 1 - Tipos de resíduos descartados na lixeira do hospital

\begin{tabular}{lcc}
\hline \multicolumn{1}{c}{ Lixo } & Especificação dos resíduos gerados & Grupo \\
\hline $\begin{array}{l}\text { Bolsas de sangue, scalp, algodão e gases } \\
\text { com resíduos de sangue }\end{array}$ & Infectante & $\mathrm{A}$ \\
\hline $\begin{array}{l}\text { Papel, isopor, garrafa pet, luva, restos e } \\
\text { embalagens de alimentos, bolsa de soro } \\
\begin{array}{l}\text { vazias, papelão, touca, máscara, avental e } \\
\text { copo descartáveis. }\end{array}\end{array}$ & Comum \\
\hline Seringas, agulhas, bisturis e vidros & & \\
\hline
\end{tabular}

Fonte: Autores

Além disso, observou-se que esses resíduos estavam acondicionados e armazenados em sacos plásticos brancos, pretos e transparentes e os perfurocortantes em caixas embaladas com sacos plásticos pretos sem terem a identificação do nome do resíduo, grupo e símbolo (figura 1A-B). Os resíduos infectantes, comuns e perfurocortantes estavam sendo despejados e agregados no mesmo local em sacos plásticos em contato com o chão, sem haver uma separação seletiva para o tipo de lixo (figura 2A-B). Na lixeira havia muitos resíduos de sangue espalhados pelo piso (figura 3A-B) e, também, o rompimento dos sacos plásticos e das caixas com resíduos comuns e os considerados perigosos, tais como copos descartáveis, restos de alimentos, seringas e vidros, além de ficarem expostos na rua. 

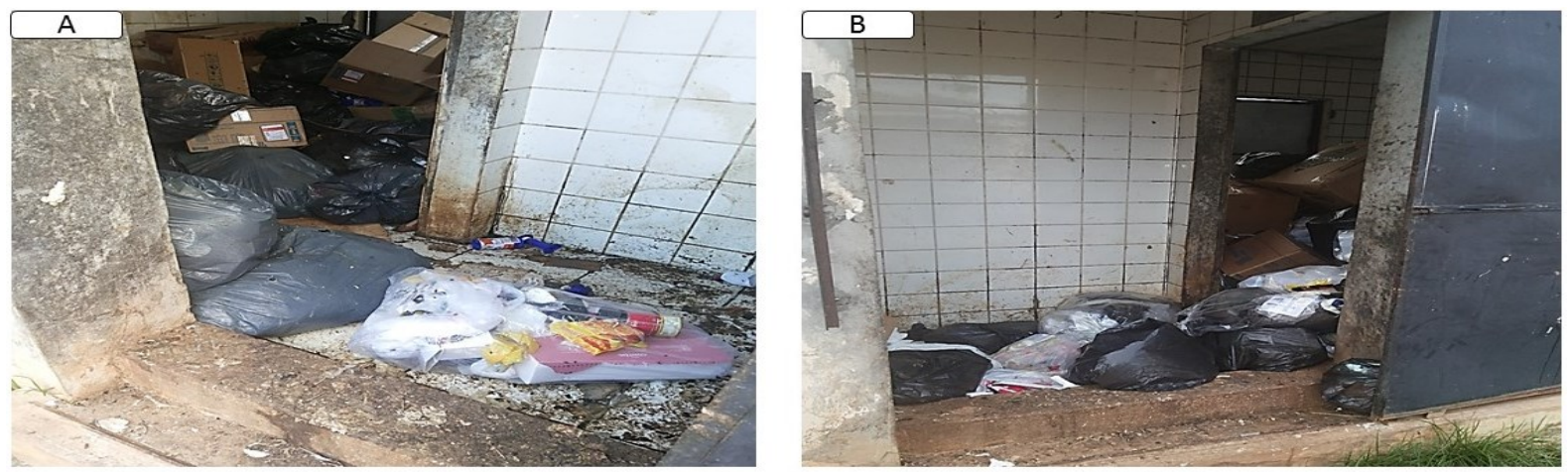

Figura 1: Descartes dos residuos na lixeira externa. A) acondicionamento e armazenamento sem identificação do tipo de residuo despejado. B) a forma de acondicionamento e armazenamento dos residuos em diversos sacos plásticos e em caixa de papelão. Fonte: Autores, 2016.
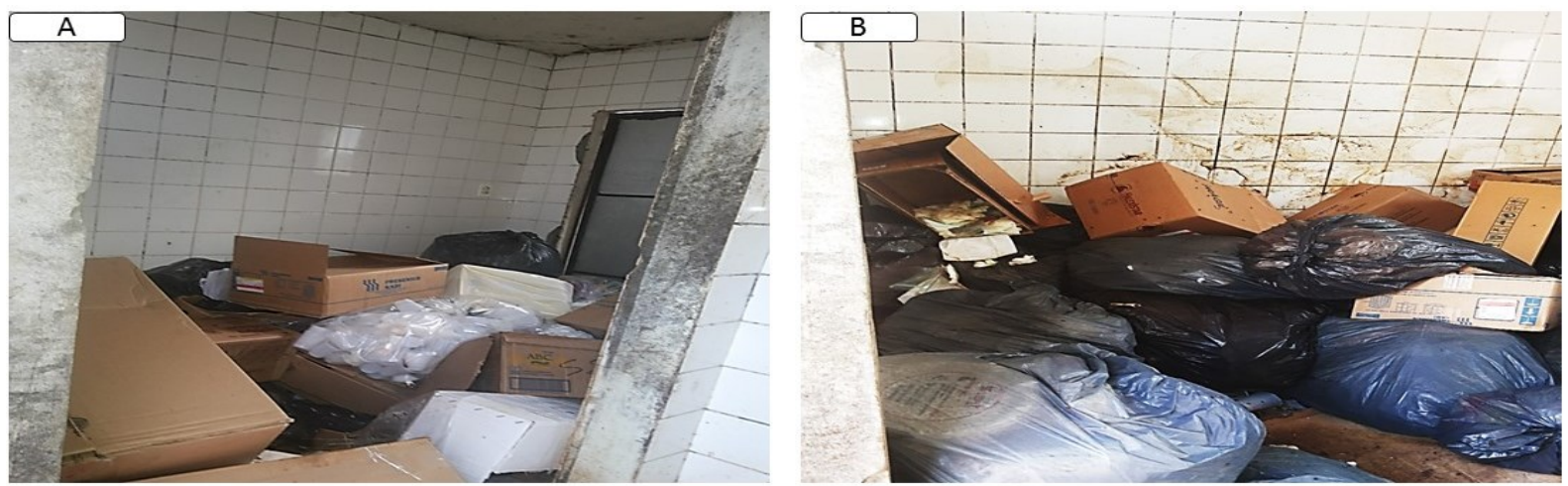

Figura 2: Armazenamento dos residuos na lixeira externa. A) agregação dos diversos residuos no mesmo espaço e em contato com o piso. B) a falta de segregação seletiva para o tipo de lixo despejado. Fonte: Autores, 2016.
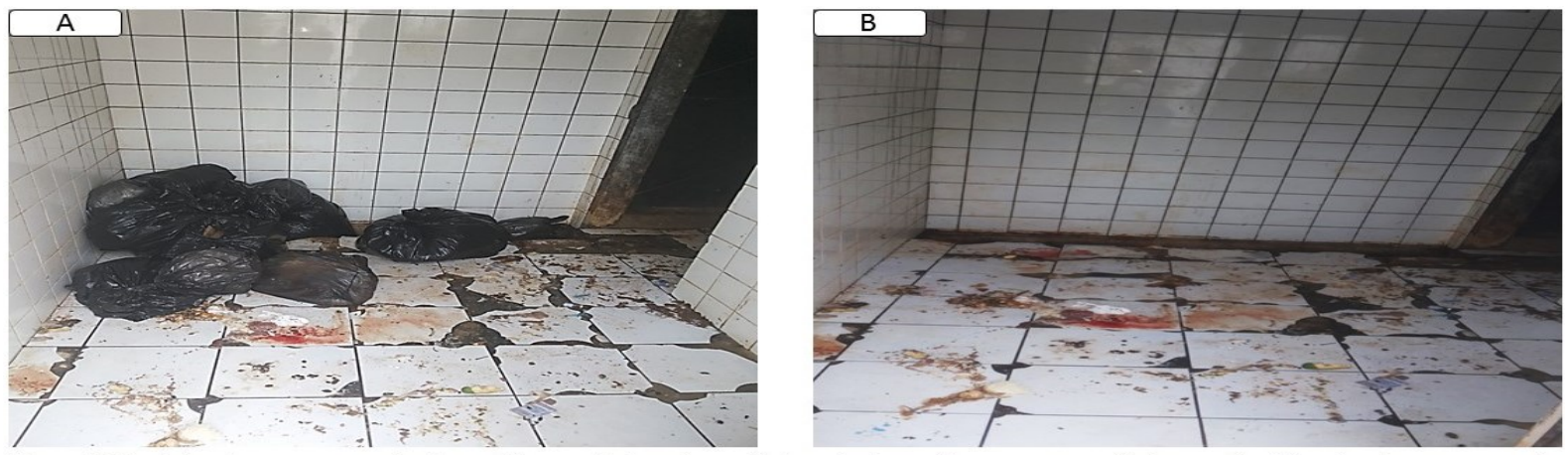

Figura 3. Condicões de armazenamento dos residuos na lixeira externa A) despejo dos resíduos em sacos plásticos pretos. B) restos de sangue no piso após o descarte e coleta dos resíduos. Fonte: Autores, 2016.

Em uma pesquisa similar realizada em uma unidade hospitalar no município de Sousa-PB, Alencar (2017) detectou a presença de resíduos do Grupo D junto com os resíduos do Grupo A, Grupo E com resíduos do grupo $\mathrm{D}$ e acondicionamento de resíduos comum e infectantes em sacos plásticos sem identificação, independentemente do tipo ou coloração. O autor afirma que os sacos estavam colocados em contato com o chão da lixeira externa e os perfurocortantes acondicionados em caixa de papelão sem identificação, assim como foram encontrados papéis, máscaras, copos descartáveis, sacos plásticos, scalps e algodão com resíduos de sangue expostos ao redor da lixeira, porém o autor destaca que os resíduos infectantes eram depositados em tonéis (reservatórios plásticos).

O lixo hospitalar deve ser tratado de forma técnica que garanta a integridade e segurança de quem coleta, transporta e das pessoas que vivem ou trabalham em locais onde são despejados, assim como

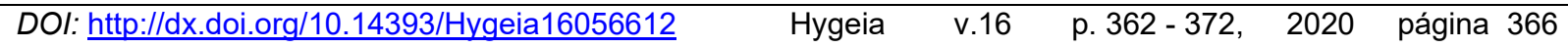


Descarte do lixo de um hospital público no município de Coari, estado do Amazonas, Brasil
Célio dos Santos Almeida Helder Manuel da Costa Santos Dartaguinan da Silva Góes Vanusa Bezerra Pachêco

prevenir as condições de armazenamento. Por isso, o Art. 14 da Resolução $n^{\circ}$ 358/2005 do CONAMA orienta que é obrigatório a segregação dos resíduos na fonte e no momento da geração conforme o Grupo A, B, C, D ou E, respeitando suas características físicas, químicas e biológicas, para fins de redução do volume dos resíduos a serem tratados e dispostos, garantindo a proteção da saúde e do meio ambiente.

Do mesmo modo, o Art. 21 da RDC n 222/2018 da ANVISA orienta que as identificações devem estar afixadas nos sacos de acondicionamento e nos carros de coleta, de forma indelével, utilizando-se e expressões símbolos, cores e frases, atendendo, além de outras exigências relacionadas à identificação de conteúdo e ao risco específico de cada grupo de resíduos.

Os sacos que acondicionam os resíduos do Grupo $D$ não precisam ser identificados, porém o grupo $A$ deverá ter, no mínimo, símbolo de risco biológico, com rótulo de fundo branco, desenho e contornos pretos, acrescido da expressão "resíduo infectante". O grupo B, símbolo e frase de risco associado à periculosidade do resíduo químico. $\mathrm{O}$ grupo $\mathrm{D}$ deve ser identificado conforme definido pelo órgão de limpeza urbana. O grupo E, símbolo de risco biológico, com rótulo de fundo branco, desenho e contorno preto, acrescido da inscrição de "resíduo perfurocortante" ou "perfurocortantes".

Vale ressaltar que, o Art. 15 indica que os resíduos do Grupo A não precisam ser obrigatoriamente tratados e devem ser acondicionados em saco branco leitoso, posteriormente, encaminhados para disposição final ambientalmente adequada e quando houver a obrigação do tratamento, o Art. 16 recomenda que devem ser acondicionados em sacos vermelhos. O Art. 18 da mesma resolução, orienta que os resíduos líquidos devem ser acondicionados em recipientes constituídos de material compatível com o líquido armazenado, resistentes, rígidos e estanques, com tampa que garanta a contenção e identificação. Quanto ao grupo D, o Art. 21 recomenda que devem ser acondicionados de acordo com as orientações dos órgãos locais responsáveis pelo serviço de limpeza urbana.

Além disso, o Art. 25 da Resolução $n^{\circ} 358 / 2005$ do CONAMA, orienta que os resíduos pertencentes ao Grupo $\mathrm{E}$ devem ter tratamento específico de acordo com a contaminação química, biológica ou radiológica e ser apresentados para a coleta acondicionados em coletores estanques, rígidos e hígidos, resistentes à ruptura, à punctura, ao corte ou à escarificação.

Ainda de acordo com a RDC $n^{\circ}$ 222/2018 da ANVISA, o Art. 34 recomenda que o abrigo externo deve ter, no mínimo, um ambiente para armazenar os coletores dos resíduos do Grupo A, podendo também do grupo $\mathrm{E}$, e outro ambiente exclusivo para armazenar os coletores do grupo $\mathrm{D}$.

A lixeira fica situada na área externa do hospital em pleno estado de deterioração, contém um portão interno com acesso para o despejo e um externo virado para as residências sem conter identificação e iluminação do local, em uma distância de aproximadamente 5 metros (figura 4A-B). Verificam-se reclamações frequentes dos moradores quanto ao odor forte causado na vizinhança, sendo que alguns, até mudaram-se de local, sobretudo pela preocupação de contraírem alguma doença, além de terem seus imóveis desvalorizados.
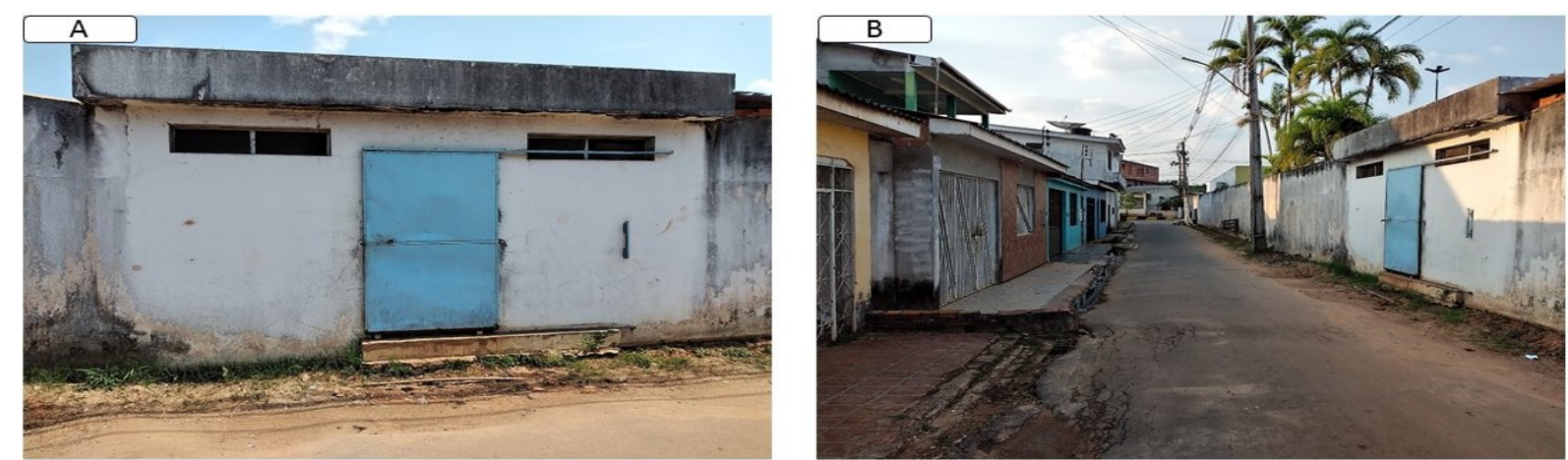

Figura 4: Lixeira externa do hospital. A) frente da lixeira sem a identificação do local e o portão externo que dá acesso a coleta dos resíduos. B) localização próximo das residências. Fonte: Autores, 2020. 
Descarte do lixo de um hospital público no município de Coari, estado do Amazonas, Brasil
Célio dos Santos Almeida Helder Manuel da Costa Santos Dartaguinan da Silva Góes Vanusa Bezerra Pachêco

Essa situação também contraria o Art. 35 da RDC n 222/2018 da ANVISA que recomenda que o abrigo externo deve ser identificado conforme os grupos armazenados, acesso restrito às pessoas envolvidas no manejo, ter ponto de iluminação, ser construído com piso, paredes e teto de material resistente, lavável e de fácil higienização, com aberturas para ventilação e com tela de proteção contra acesso de vetores, além disso, possuir porta com abertura para fora, provida de proteção inferior contra roedores e vetores, com dimensões compatíveis com as dos coletores utilizados.

O acesso do caminhão coletor do lixo hospitalar a lixeira externa é feito por uma rua estreita que separa as residências da lixeira. Os garis, funcionários da prefeitura municipal de Coari, recolhiam os resíduos usando máscara, botas de borracha, luvas, capa e calça de plástico como equipamento de segurança (figura 5A). Além disso, observou-se que o caminhão recolhia não só os resíduos do hospital, mas também o lixo de outras unidades de saúde que, posteriormente, eram despejados no lixão a céu aberto (figura 5B). Foram encontrados expostos resíduos como seringas, agulhas, bisturis, scalps e bolsas de sangue (figura 6), identificados como infectantes no saco plástico rosa. No lixão, a retroescavadeira misturava os resíduos de origem domiciliar e hospitalar sem qualquer preocupação seletiva.
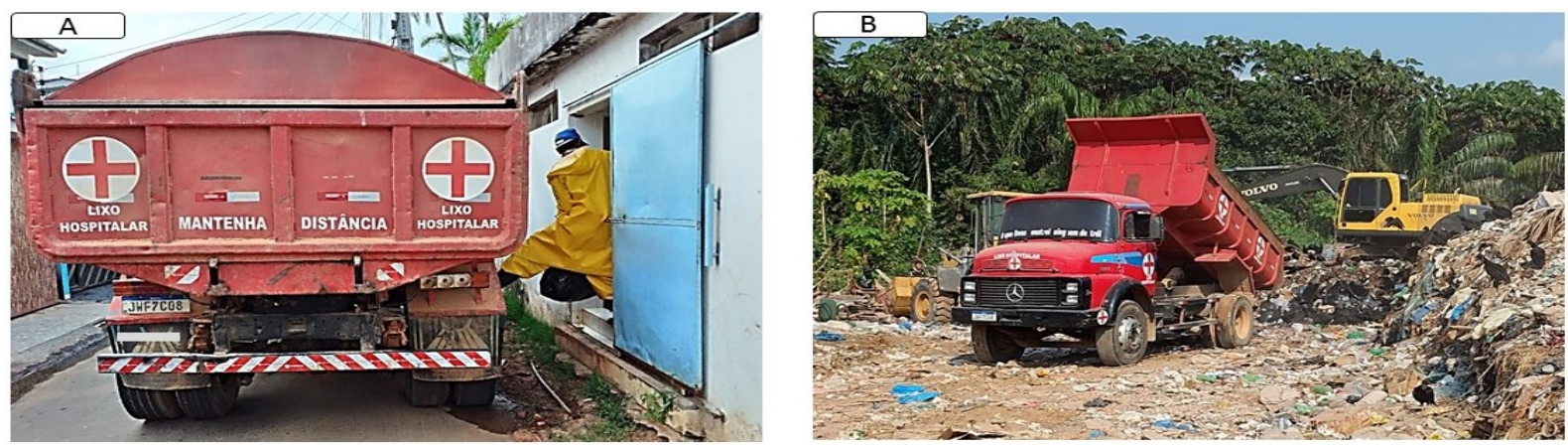

Figura 5: Coleta, transporte e despejo dos residuos. A) gari coletando os residuos na lixeira externa do hospital. B) caminhão coletor despejando os resíduos no lixão a céu aberto. Fonte: Autores, 2020.

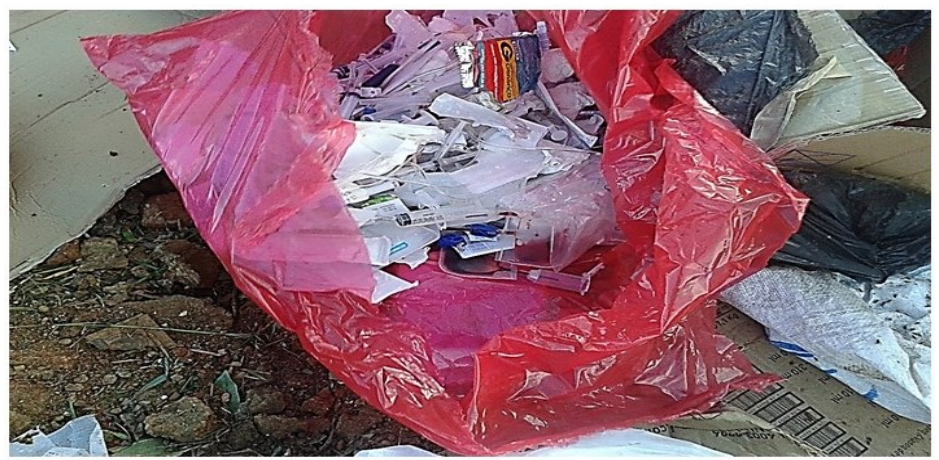

Figura 6: Resíduos infectantes e perfurocortantes expostos no solo após o despejo no lixão. Fonte: Autores, 2017

Além dos impactos ambientais, a exposição desses resíduos traz sérios riscos de acidentes aos funcionários que coletam e transportam, bem como à saúde dos residentes que vivem próximos do lixão. Situações semelhantes foram detectadas por Rocha et al. (2007) ao encontrarem luvas de procedimentos, seringas, frascos de soro e de medicamentos líquidos e outros materiais de uso hospitalar, expostos fora de sacos plásticos em meio aos resíduos domiciliares no lixão em um Município da região de Maringá-PR. O mesmo foi comprovado por Amate et al. (2017) em uma pesquisa realizada com catadores do lixão do Distrito Federal-DF, que relataram já terem encontrado resíduos perfurocortantes, remédios, pedaços de corpo humano, presenciado a morte de outro trabalhador no lixão, assim como sofrido cortes e perfurações com agulhas e bisturis. 
Descarte do lixo de um hospital público no município de Coari, estado do Amazonas, Brasil
Célio dos Santos Almeida Helder Manuel da Costa Santos Dartaguinan da Silva Góes Vanusa Bezerra Pachêco

Em relação ao descarte realizado pelos estabelecimentos, Bento e Costa (2015) mencionaram que $37,4 \%$ dos resíduos de serviços de saúde são incinerados, $21,7 \%$ são destinados ao aterro sanitário, $16,6 \%$ autoclave, $13,3 \%$ despejados no lixão, 5,8\% vala asséptica e 5,2\% microondas.

A cidade de Coari tem um aterro sanitário construído no $\mathrm{km} \mathrm{4,5}$ da estrada Coari-Itapeuá seguindo normas operacionais que permitem a confinação segura em termo de poluição ambiental e proteção à saúde pública, mas sua localização geográfica é inadequada, por não estar a uma distância segura do aeroporto, conforme preconiza a legislação, o que impede o seu uso integral. Devido a isso, o lixo recolhido da cidade é jogado no lixão que fica em uma área situada na estrada Coari-Itapeuá à cerca de $5 \mathrm{~km}$ da área urbana.

A maioria dos municípios brasileiros, como Coari, ainda depositam de modo inadequado seus resíduos em lixões ou aterros controlados que pouco se diferenciam dos lixões, colocando em risco a saúde pública e a degradação do meio ambiente. Ambos os destinos não são recomendados pelos danos ambientais que causam por não atenderem as normas de controle e por isso estão proibidos no Brasil. Então, recomenda-se o aterro sanitário onde a disposição dos resíduos segue uma série de normas e procedimentos técnicos visando minimizar os impactos ao meio ambiente.

A Lei n. 12.305/2010 que institui a Política Nacional de Resíduos Sólidos (PNRS) estabeleceu que prefeituras se ajustassem as novas regras até o final de 2014 (BRASIL, 2010). No entanto, em julho de 2015, o Senado estendeu a data-limite para o fim dos lixões. Além das capitais e regiões metropolitanas, os municípios de fronteira e os que contam com mais de 100 mil habitantes, com base no Censo de 2010, ganharam prazo até 2019. Cidades com população entre 50 e 100 mil habitantes têm até 31 de julho de 2020 para resolver essa questão. Já os municípios menores, com menos de 50 mil habitantes, devem estar de acordo com a lei até 31 de julho de 2021.

Partindo dessa visão, a resolução $n^{\circ} 358 / 2005$ do CONAMA, por meio do Art. 15 orienta que os resíduos infectantes, como as bolsas de sangues devem ser submetidos a processos de tratamento em equipamento que promova redução de carga microbiana compatível com nível III de inativação microbiana e encaminhados para aterro sanitário licenciado ou local devidamente licenciado para disposição final. O Art. 24 da resolução diz que os resíduos do Grupo D quando não forem passíveis de processo de reutilização, recuperação ou reciclagem devem ser encaminhados para aterro sanitário de resíduos sólidos urbanos, devidamente licenciado pelo órgão ambiental competente, no entanto quando for passível de processo de reutilização, recuperação ou reciclagem devem atender as normas legais de higienização e descontaminação.

Para os materiais perfurocortantes, o Art. 86 da RDC $n^{\circ}$ 222/2018 da ANVISA recomenda que devem ser descartados em recipientes identificados, rígidos, providos com tampa, resistentes à punctura, ruptura e vazamento. Além disso, quando contaminados por agentes biológicos, químicos e substâncias radioativas devem ter seu manejo de acordo com cada classe de risco associada, como descrito no Art. 88, assim como o recipiente de acondicionamento deve conter a identificação de todos os riscos presentes. No entanto, as seringas, agulhas e os demais materiais perfurocortantes que não apresentem risco químico, biológico ou radiológico, o Art. 89 diz que não precisam de tratamento prévio, estando a disposição final ambientalmente adequada. O Art. 91 XII da resolução ainda recomenda o uso de equipamentos de proteção individual e coletiva para a manipulação dos resíduos como uma das formas de evitar o risco de contaminação.

Apesar das dificuldades enfrentadas pelos estabelecimentos quanto a segregação, acondicionamento, armazenamento, identificação, coleta, transporte e despejo final, Ferreira e Martins (2016) citam que ainda há uma preocupação sobre o gerenciamento adequado dos resíduos dos serviços de saúde, principalmente aqueles gerados pelos hospitais.

Em um estudo realizado por Melo et al. (2013) sobre o gerenciamento dos resíduos dos serviços de saúde em 15 unidades de saúde no município de Jataí-GO, verificaram que a maioria priorizou as etapas de segregação, identificação e acondicionamento dos resíduos infectantes, comuns e perfurocortantes.

Araújo (2018), avaliando a gestão dos resíduos sólidos dos serviços de saúde em hospitais do município de João pessoa-PB, obteve resultados que demonstraram serias dificuldades na segregação correta dos resíduos e armazenamento dos resíduos infectantes, ainda, verificou que os resíduos do Grupo A, B, E eram recolhidos por empresa terceirizada especializada no tratamento dos resíduos dos serviços de saúde e do Grupo $D$ pelos órgãos de limpeza pública e associações de materiais

DOI: http://dx.doi.org/10.14393/Hygeia16056612 $\quad$ Hygeia $\quad$ v.16 $\quad$ p. 362 - 372, 2020 página 369


recicláveis, posteriormente, incinerados e despejados em aterros e na central de tratamentos de resíduos.

Avaliando o gerenciamento dos resíduos em 6 hospitais na região de Inconfidentes-MG aferindo em regularidade quanto as normas, Valadares (2009) verificou que todos os hospitais possuíam o plano para o seu gerenciamento e que adotavam rigorosamente as medidas de acordo com a RDC $n^{\circ} 306 / 04$ da ANVISA.

O gerenciamento desses resíduos ainda vem sendo discutido no Brasil e sobretudo em instituições de saúde, devidos as dificuldades em seguir o procedimento em acordo com as normas e resoluções por meio do plano de gerenciamento dos resíduos, como exemplo, o hospital da rede pública no município de Coari.

Os cuidados com os resíduos hospitalares devem seguir normas rigorosas determinadas pela Agência Nacional de Vigilância Sanitária (ANVISA) e pelo Conselho Nacional de Meio Ambiente (CONAMA), assim como devem cumprir as normas dispostas na Resolução RDC n 222/2018 da Anvisa e da Resolução n $n^{\circ} 358 / 2005$ do CONAMA, pois é onde estão estabelecidas as recomendações sobre o gerenciamento correto dos resíduos dos serviços de saúde.

\section{CONCLUSÃO}

Os resultados evidenciaram uma grande dificuldade do hospital em manter um gerenciamento correto para o tratamento, segregação, acondicionamento, identificação, armazenamento, coleta, transporte e despejo final dos resíduos, pois estavam sendo descartados de forma inadequada e, portanto, em desacordo com a legislação em vigor. Desse modo, os funcionários responsáveis pela coleta e a sociedade ficavam vulneráveis a todos os tipos de vírus e bactérias provenientes desses resíduos que podem causar sérios prejuízos à saúde pública e ao meio ambiente.

Os dados obtidos também servem como conscientização para que a unidade hospitalar venha a cumprir a legislação sobre o gerenciamento correto dos resíduos dos serviços de saúde, garantindo a segurança e prevenção dos riscos de contaminação dos funcionários que manuseiam, da sociedade e do meio ambiente.

Recomenda-se que as autoridades responsáveis pelos resíduos, especialmente os hospitalares, se preocupem com o seu gerenciamento desde o acondicionamento até ao seu destino, para que não ocorra a mistura dos resíduos hospitalares com os de origem doméstica e comercial e que o destino não seja o lixão.

\section{REFERÊNCIAS}

ALENCAR, L. D. Gerenciamento dos resíduos de serviços de saúde de uma unidade hospitalar pública no município de Sousa-PB. 2017. 133f. Dissertação (Mestrado em Recursos Naturais) Centro de Tecnologia e Recursos Naturais, Universidade Federal de Campina Grande, 2017.

ALVES, S. B. Manejo de resíduos de serviços de saúde na atenção básica. 2010. 145f. Dissertação (Mestrado em Enfermagem) - Faculdade de enfermagem, Universidade Federal de Goiás, Goiânia, 2010.

AMATE, E. M.; CARNEIRO, F. F.; HOEFEL, M. G. L. Percepções dos catadores sobre resíduos dos serviços de saúde (rs) no lixão da estrutural. Revista Eletrônica Gestão e Saúde, Brasília, v. 8, n. 1, p. 1319-1336, 2017.

ANVISA. Resolução (RDC) n 222, de 7 de março de 2018. Brasília Regulamenta as boas práticas de gerenciamento dos resíduos de serviços de saúde e dá outras providências. Diário Oficial da União: Brasília, DF, n 61, 29 março. 2018.

ARAÚJO, E. S. Avaliação da gestão dos resíduos sólidos de serviços de saúde em hospitais do município de João Pessoa-PB. 2018. 95f. Dissertação (Mestrado em Engenharia Ambiental) Universidade da Paraíba, 2018.

BARROS, D. X.; FRANCO, L. C.; TIPPLE, A. F. V.; BARBOSA, M. A.; SOUZA, A. C. S. Exposição a material biológico no manejo externo dos resíduos de serviço de saúde. Revista Cogitare Enfermagem, v. 15, n.1, p. 82-85, 2010. https://doi.org/10.5380/ce.v15i1.17176

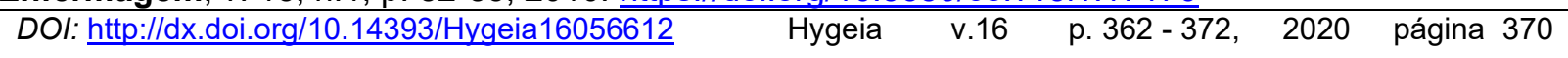


Descarte do lixo de um hospital público no município de Coari, estado do Amazonas, Brasil
Célio dos Santos Almeida Helder Manuel da Costa Santos Dartaguinan da Silva Góes Vanusa Bezerra Pachêco

BARROS, P. M. G. A.; MELO, D. C. P.; LINS, E. A. M.; SILVA, R. F. Percepção dos profissionais de saúde quanto a gestão dos resíduos de serviço de saúde. Revista Ibero Americana de Ciências Ambientais, v.11, n.1, p. 201-210, 2020. https://doi.org/10.6008/CBPC2179-6858.2020.001.0019

BENTO, D. G.; COSTA, R. Estado da arte acerca dos resíduos de serviço de saúde. Revista Eletrônica Estágio Saúde, v. 4, n. 2, p. 125-138, 2015.

BORGES, A. M. M.; TIMÓTEO, J. E. N.; BRASIL, M. A.; BRITO, A. B.; PINTO, A. G. A.; FONSECA, F. L. A. Gerenciamento de resíduos em serviços de saúde do sertão nordestino. Revista Saúde e Meio Ambiente, v. 5, n. 2, p. 93-105, 2016. https://doi.org/10.24302/sma.v5i2.1070

BRASIL. Lei $n^{\circ}$ 12.305, de 2 de agosto de 2010. Institui a Política Nacional de Resíduos Sólidos. Diário Oficial da União: Brasília, DF, p. 2, 3 ago. 2010.

CAFURE, V. A.; GRACIOLLI, S. R. P. Os resíduos de serviço de saúde e seus impactos ambientais: uma revisão Bibliográfica. Revista Interações, Campo Grande, v. 16, n. 2, p. 301-314, 2015. https://doi.org/10.1590/151870122015206

CAMARGO, M. E.; MOTTA, M. E. V.; LUNELLI, M. O.; SEVERO, E. A. Resíduos sólidos de serviço de saúde: um estudo sobre o gerenciamento. Revista Scientia Plena, v. 5, n.7, p. 1-14, 2009.

CONAMA. Resolução $n^{\circ}$ 358, de 29 de abril de 2005. Dispõe sobre o tratamento e a disposição final dos Resíduos dos Serviços de saúde e dá outras Providências. Diário Oficial da União: Seção 1, Brasília, DF, n 84, p. 63-65, 4 maio. 2005.

COSTA, W. M.; FONSECA, M. C. G. A importância do gerenciamento dos resíduos hospitalares e seus aspectos positivos para o meio ambiente. Revista Brasileira de Geografia Médica e da Saúde, v. 5, n. 9 , p. 12-31, 2009.

COTRIM, O, S.; SLOB, E.; DEFFUNE, E. Importância da segregação de materiais no gerenciamento de lixo hospitalar na área de hemoterapia. Revista Caderno de Saúde e Desenvolvimento, ano 1. n.1, p. 59-73, jul./dez. 2012.

ERDTMANN, B. K. Gerenciamento dos resíduos de serviço de saúde: biossegurança e o controle das infecções hospitalares. Revista Texto Contexto Enfermagem, v. 13, p. 86-93, 2004. https://doi.org/10.1590/S0104-07072004000500010

FERREIRA, N. S.; MARTINS, A. J. Gerenciamento de resíduos de serviços de saúde: uma revisão bibliográfica. Revista Eletrônica Atualiza Saúde, Salvador, v.3, n.3, p.114-124, jan./jun. 2016.

GARCIA, L. P.; RAMOS, B. G. Z. Gerenciamento dos resíduos de serviços de saúde: uma questão de biossegurança. Revista Caderno de Saúde Pública, Rio de Janeiro, v. 20, n. 3, p. 744-752, mai./jun. 2004. https://doi.org/10.1590/S0102-311X2004000300011

GESSNER, R.; PIOSIADLO, L. C. M.; FONSECA, R. M. G. S.; LAROCCA, L.M. O manejo dos resíduos dos serviços de saúde: um problema a ser enfrentado. Revista Cogitare Enfermagem, v. 18, n. 1, p. 117-123, jan./mar. 2013. https://doi.org/10.5380/ce.v18i1.31316

GIL, A. C. Como elaborar projetos de pesquisa. Capa Leonardo Hermano. $4^{\circ}$ ed. São Paulo: Atlas, 2002. 176p. ISBN: 85-224-3169-8.

GONSALVES, E. P. Conversas sobre iniciação à pesquisa científica. Editoração eletrônica Sonia Travisk. Revisão de textos Douglas Dias Ferreira, $2^{\circ}$ ed. Campinas: Alínea, 2001.

HADDAD, C. M. C. Resíduos de serviços de saúde de um hospital de médio porte do município de Araraquara: subsídios para elaboração de um plano de gerenciamento. 2006. 137f. Dissertação (Mestrado em Desenvolvimento Regional e Meio Ambiente) - Centro Universitário de Araraquara, Araraquara, 2006.

INSTITUTO BRASILEIRO DE GEOGRAFIA E ESTATÍSTICA. IBGE 2019: População estimada. Coari, 2019. Disponível em: https://cidades.ibge.gov.br/. Acesso em: 23 de jul. 2020.

MACHADO, N, L.; MORAES, L. R. S. RSSS: revisitando as soluções adotadas no brasil para tratamento e destino final. Revista Engenharia Sanitária e Ambiental, vol. 9, n.1, p. 55-64, jan./mar. 2004. 
Descarte do lixo de um hospital público no município de Coari, estado do Amazonas, Brasil
Célio dos Santos Almeida Helder Manuel da Costa Santos Dartaguinan da Silva Góes Vanusa Bezerra Pachêco

MADERS, G. R.; CUNHA, H. F. A. Análise da gestão e gerenciamento dos resíduos de serviços de saúde (RSS) do Hospital de Emergência de Macapá, Amapá, Brasil. Revista Engenharia Sanitária e Ambiental, v. 20, n. 3, p. 379-388, 2015. https://doi.org/10.1590/S1413-41522015020000137607

MARCONI, M. A.; LAKATOS, E. M. Fundamentos de metodologia científica. Capa Leonardo Ferreira Leite. $5^{\circ}$ ed. São Paulo: Atlas, 2003. ISBN: 85-224-3397-6.

MEDEIROS, G. A.; REIS, F. A. G. V.; COSTA, F. B.; BENAGLIA, G. C.; SCOLARI, M. C.; FIORINI, P. A.; MIRANDA, P. A. M.; PASSONI, V. Diagnóstico do lixão do município de Vargem Grande do Sul, no Estado de São Paulo. Revista Engenharia Ambiental, Espírito Santo do Pinhal, v 5, n.3, p. 1-16, 2008.

MELO, C. P.; BARBOSA, L. B.; SOUZA, M. R.; BARCELOS, I. S. C. Estudo descritivo sobre o gerenciamento de resíduos de serviços de saúde no município de Jataí, Goiás, 2010. Revista Epidemiologia e Serviços de Saúde, Brasília, v, 22, n.3, p. 517-524, jul./set. 2013. https://doi.org/10.5123/S1679-49742013000300017

MENDES, A. A. A percepção ambiental dos resíduos de serviço de saúde-rss da equipe de enfermagem de um hospital filantrópico de Araraquara-SP. 2005. 110f. Dissertação (Mestrado em Desenvolvimento Regional e Meio Ambiente) - Centro Universitário de Araraquara, Araraquara, 2005.

NETO, A. L. G. C.; RÊGO, A. R. F.; LIRA, A.; ARCANJO, J. G.; OLIVEIRA, M. M. Consciência ambiental e os catadores de lixo do lixão da cidade do Carpina-PE. Revista Eletrônica do Mestrado em Educação Ambiental, v.19, p. 99-109, jul./dez. 2007.

POZZETTI, V. C.; MONTEVERDE, J. F. S. Gerenciamento ambiental e descarte do lixo hospitalar. Revista Vereadas do Direito, Belo Horizonte, v. 14, n. 28, p.195-220, jan./abril. 2017. https://doi.org/10.18623/rvd.v14i28.949

PRODANOV, C. C.; FREITAS, E. C. Metodologia do trabalho científico: métodos e técnicas da pesquisa e do trabalho acadêmico. $2^{\circ}$ ed. Novo Hamburgo: Feevale, 2013.

ROCHA, D, P.; CONSONI, V. H.; PEREIRA, A. P. C. Carência no armazenamento, gerenciamento e destinação do lixo hospitalar em um Município da região de Maringá-PR. Revista Uningá, n.11, p. 145152, jan./mar. 2007

SALLES, C. L. S. Acidentes de trabalho ocorridos com os trabalhadores da saúde nos diferentes processos de um plano de gerenciamento de serviços de saúde. 2008. 76f. Dissertação (Mestrado em Enfermagem) - Universidade Guarulhos, Guarulhos, 2008.

SANTANA, G. M. Aplicação do QRcode para rastreamento do lixo hospitalar. 2016. 46f. Trabalho de Conclusão de Curso (Especialização em Gestão da Tecnologia da Informação e Comunicação) Universidade Tecnológica do Paraná, Curitiba, 2016.

SOUZA, A. P. Análise da capacidade atual de tratamento e disposição final de resíduos de serviço de saúde gerados no estado do rio de janeiro, com recorte da região hidrográfica do guandu. 2011. 124f. Dissertação (Mestrado em Planejamento Energético) - Universidade Federal do Rio de Janeiro, Rio de Janeiro, 2011.

SPINA, M. I. A. Características do gerenciamento dos resíduos sólidos dos serviços de saúde em Curitiba e análise das implicações socioambientais decorrentes dos métodos de tratamento e destino final. Revista RA'EGA, Curitiba, n. 9, p. 95-106, 2005. https://doi.org/10.5380/raega.v9i0.3450

VALADARES, C. M. Gerenciamento de resíduos de serviços de saúde: estudo em hospitais da região. 2009. 147f. Dissertação (Mestrado em Engenharia Ambiental) - Universidade Federal de Ouro Preto, Ouro Preto, 2009.

ZAMBELlo, A. V.; SOARES, A. G.; TAUIL, C. E.; DONZELLI, C. A.; FONTANA, F.; CHOTOLLI, W. P. Metodologia da pesquisa e do trabalho científico. Organizador Thiago Mazucato. $1^{\circ}$ ed. Penápolis: FUNEPE, 2018. 95p. ISBN 97885-93683-03-9. 